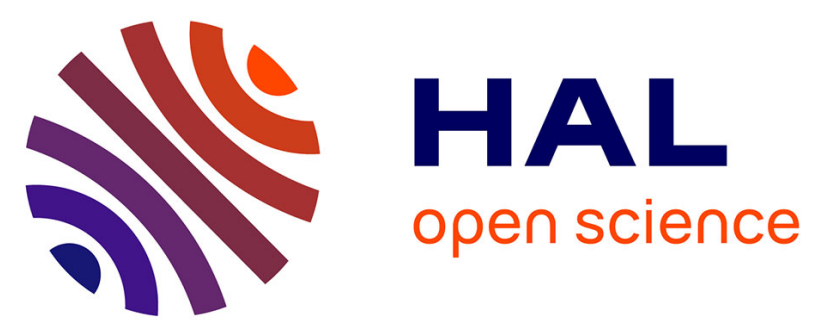

\title{
Reassessment of paleointensity estimated of a single lava flow from Xitle volcano, Mexico, by means of multispecimen domain-state corrected
}

L.M. Alva-Valdivia, M.A. Bravo-Ayala, P. Camps, A.N. Mahgoub, Thierry Poidras

\section{To cite this version:}

L.M. Alva-Valdivia, M.A. Bravo-Ayala, P. Camps, A.N. Mahgoub, Thierry Poidras. Reassessment of paleointensity estimated of a single lava flow from Xitle volcano, Mexico, by means of multispecimen domain-state corrected. Journal of South American Earth Sciences, 2020, 100, pp.102549. 10.1016/j.jsames.2020.102549 . hal-02871023

\section{HAL Id: hal-02871023 \\ https://hal.umontpellier.fr/hal-02871023}

Submitted on 31 Jul 2020

HAL is a multi-disciplinary open access archive for the deposit and dissemination of scientific research documents, whether they are published or not. The documents may come from teaching and research institutions in France or abroad, or from public or private research centers.
L'archive ouverte pluridisciplinaire HAL, est destinée au dépôt et à la diffusion de documents scientifiques de niveau recherche, publiés ou non, émanant des établissements d'enseignement et de recherche français ou étrangers, des laboratoires publics ou privés. 
112 Géosciences Montpellier, CNRS and University Montpellier, Montpellier, France

123 Geology Department, Assiut University, Assiut 71516, Egypt published PI data obtained by use of Thellier and microwave experiments gave a mean of

$27 \quad 134$ of these data can be considered reliable, as they meet a set of selection criteria designed 
28 in this study. These evaluated data gave an average mean of $62.0 \pm 9.3 \mu T$. In order to

29 strengthen the PI estimates of Xitle, we conducted a multispecimen domain-state corrected

30 (MSP-DSC) method along one vertical $(\sim 4.5 \mathrm{~m})$ and three horizontal $(\sim 1.25 \mathrm{~m}$, each)

31 profiles. Top horizontal and vertical profiles have fulfilled a stringent criteria set while central

32 and bottom profiles exceeded the alteration check criteria limit and thus are considered

33 unreliable. Accordingly, Xitle PI mean derived from MSP-DSC experiment is calculated at

$34 \quad 60.5 \pm 4 \mu T$, thus in a good agreement with the mean value estimated from previous filtered

35 data. The result and success rate obtained may be ascribed to cooling rate variations

36 commonly found at the lava profile, and indicate that MSP-DSC outcome is governed by the

37 magnetic properties such as the domain-size behavior and the thermal stability of the

38 magnetic carriers present in the treated specimens, as in the conventional Thellier \&

39 microwave-style experiments. From these two averages, a combined mean and standard

40 deviation of $61.9 \pm 9 \mu T$ is calculated, which technically is considered the most probable

41 intensity estimate at the Xitle eruption time, $c a .370 \mathrm{AD}$.

42 Keywords: paleointensity; lavas; rock magnetic properties; multispecimen method; Xitle; 43 Mexico

\section{Introduction}

48 Over the long history of our planet, the magnetic field generated in the liquid outer core

49 changed on different time scales from years to billions of years. Understanding the spatio-

50 temporal evolution of this field requires careful determination of its strength. Because of its

51 large contributions in deciphering the geodynamo behavior (Biggin et al., 2012) and

52 improving the global geomagnetic field models (e.g., SHA.DIF.14k, Pavón-Carrasco et al.,

53 2014), several methods were proposed to obtain a reliable estimate of the PI: the classical 
54 Thellier-Thellier experiment (Thellier \& Thellier 1959) and other protocols (e.g., Coe et al., 55 1967; Aitken et al., 1988; Tauxe and Staudigel, 2004); the Shaw method (Shaw, 1974) and 56 its variants (e.g. Tsuanakawa and Shaw, 1994); pseudo-Thellier (Tauxe et al., 1995); the 57 microwave technique (Hill \& Shaw 1999); and the recent approach of multispecimen 58 (Biggins and Poidras, 2006; Dekkers and Böhnel, 2006; Fabian and Leonhardt, 2010). 59 Despite the improvements achieved in the laboratory protocols, these methods give reliable 60 intensity with a low success rate (generally less than 30\%) from basalts, the material of 61 interest in this study. This was showed by comparing PI data retrieved from historically 62 erupted lava flows, such as those in Hawaii (e.g. Yamamoto et al., 2003; Böhnel et al., 2011; 63 Grappone et al., 2019) and Etna (e.g. Hill and Shaw, 1999; De Groot et al., 2013), with the 64 actual geomagnetic field intensity that is well known from geomagnetic observatories. Th 65 elow success rate in the PI methods to recover the expected field intensity with high accuracy 66 could be attributed to several reasons, including the presence of non-ideal physical and 67 magnetic properties, magneto-mineralogical alteration, the cooling rate difference and 68 presence of local magnetic field effects (Stacey \& Banerjee 1974). From the PI point of view, 69 lava samples must contain ferromagnetic particles of single domain ( $\mathrm{SD} ;<\sim 80 \mathrm{~nm}$ ) to 70 pseudo-SD (PSD; $<\sim 0.1 \mu \mathrm{m}$ ) size . This condition however, is not easily reached because in 71 naturally cooled lavas there are always contributions from grains larger than $\sim 1.0 \mu \mathrm{m}$, of 72 multidomain (MD) size. In this context, Cromwell et al. (2015) have showed the capability 73 of subaerial basaltic volcanic glass to give accurate field intensity as they have cooled quickly 74 and behaves as SD particles. Unfortunately, these glassy samples are not usually available, 75 but indeed the most commonly encountered material is a lava flow which depends on its 
76 position and cooling rate can take from days to several months to cool, and thus a wide range

77 of domain size is expected.

78 All these factors may be responsible for over- or under-estimating the PI values. Xitle lava

79 flows (Fig. 1) allowed to illustrate and discuss this problem because dozens of previous PI

80 estimates conducted on them have commonly yielded different mean values with large

81 dispersions. These data were mainly obtained by means of Thellier method and some others

82 were provided by means of microwave and Shaw techniques. It should be mentioned here

83 that previous data are of uneven quality and thus in the next section we will discuss their

84 reliability based on today's set criteria parameters (Paterson et al., 2014; Thellier et al., 2014).

85 The present work was designed to reinforce Xitle PI estimates and to reduce its errors through

86 applying MSP-DSC method along one vertical (ca. 4.5m) and three horizontal profiles.

87 Providing a new reliable PI value for a dated flow unit is important to (among others) enhance

88 the global harmonic spherical models of the secular variation of the geomagnetic field over

89 the last millennia (e.g. Nilsson et al., 2014 and Pavón-Carrasco et al., 2014) and improve our

90 knowledge of the local field intensity behavior in central Mexico at $c a .370$ AD.

\section{$91 \quad$ 2. Geological setting and sampling}

92 The study profile $\left(19.328^{\circ} \mathrm{N} ; 99.189^{\circ} \mathrm{W}\right)$ is part of the flow VI of Xitle (Fig. 1) located

93 inside the campus of UNAM (Universidad Nacional Autónoma de Mexico). Xitle lies in the

94 central sector of the Trans-Mexican Volcanic Belt (TMVB, Fig. 1) which is an E-W trending

95 zone of ca.1000 km length extending from the Pacific Ocean to the Gulf of Mexico. The

96 TMVB is divided in western, central, and eastern sectors. The Sierra de Chichinautzin

97 Volcanic Field (SCVF) is located in the central sector (inset Fig. 1).

98 The SCVF contains high concentration of monogenetic volcanoes with about 220 Quaternary 
99 volcanic products including cinder cones and lava flows (Siebe, 2000; Rodríguez-Trejo et 100 al., 2019) of wide compositional range. Xitle is considered as the youngest monogenetic 101 volcano of the SCVF with a radiocarbon age of 1530-1630 uncalibrated yr BP (cal. 370 \pm 60 102 AD; Siebe et al., 2004; Arce et al., 2013). Xitle eruption is an example of the impact of 103 volcanic disaster on the human population, as supposedly it had damaged the pre-Hispanic 104 settlements around Cuicuilco pyramid (Fig. 1) which prompted them to emigrate (Siebe, 105 2000), as like in the historical eruptions of the Jorullo (1759-1774 AD; Guilbaud et al., 2011; 106 Rasoazanamparany et al., 2016; Alva-Valdivia et al., 2019) and Paricutin (1943-1952 AD; 107 Luhr and Simkin, 1993; Pioliet al., 2008) monogenetic volcanoes.

108 The sampled site was selected so that the bottom and top of the lava section (Fig. 3) are 109 visible. Sampling was done using a portable gasoline powered drill, and 72 core samples, 110 each with 5-10 $\mathrm{cm}$ long and $2.5 \mathrm{~cm}$ diameter, were collected. In this study, four profiles (Fig.

111 3) were taken and distributed as follow: one vertical profile (V) of $c a .4 .5 \mathrm{~m}$ thickness and 112 composed of 43 cores; and three horizontal profiles (H) of $c a .1 .25 \mathrm{~m}$ length for each: top 113 horizontal (HT) of 11 cores; middle horizontal (HM) of 10 cores; and the bottom horizontal 114 (HB) of 11 cores.

\section{3. Previous PI studies}

116 Nine PI studies were conducted on Xitle lava flows by means of the double heating Thellier 117 (Nagata et al., 1965; Urrutia-Fucugauchi, 1996; Gonzales et al., 1997; Alva Valdivia, 2005; 118 Böhnel et al., 1997; Morales et al., 2001, 2006; Mahgoub et al., 2019); microwave (Böhnel 119 et al., 2003); and Shaw (Urrutia-Fucugauchi, 1996; Gonzales et al., 1997) methods. Sampling 120 in five of these studies were collected randomly and its coordinates are of low precision 121 which makes us unable to define target flow unit in some of them. On the other hand, three 
122 studies (Böhnel et al. , 1997; 2003; Alva-Valdivia et al., 2005) were designed so as to sample 123 vertical profiles over a specific cooling unit.

124 Two studies (Böhnel et al., 2003; Mahgoub et al., 2019) were carried out on pottery fragments 125 that were reheated by Xitle eruption and thus acquired their magnetization at the same time. 126 Böhnel et al. (2003) have performed microwave experiments on lavas and pottery fragments, 127 with the field applied perpendicular and parallel to the their NRMs. We note also that PI data 128 points presented in Böhnel et al. (1997) have been re-analyzed by Böhnel et al. (2003) 129 applying a stringent set of selection criteria. At this point, it must be stated that Böhnel et al. 130 (1997) carried out their study rather to find out how PI varies over the Xitle flow (see section 131 5.2) and if there is a relation between rock magnetic properties and success rate, therefore 132 they have not used a very strict selection criteria. Morales et al. (2006) tried to figure out the 133 cause of PI dispersion through conducting cooling rate correction. Based on their results, a 134 significant decrease in PI-dispersion was obtained (from 7.5 to $3.5 \mu \mathrm{T}$ ), thus they have 135 claimed that cooling-rate effect may have a prominent role in the observed dispersion. There 136 are two points to be mentioned in this context: the first is that Morales et al. (2006) have 137 obtained positive and negative corrections from nearby samples (of 10-20 cm distance) that 138 should have a very similar cooling rate. Secondly, if the change in the cooling rate is the 139 reason for the PI-dispersion, then, reasonably, Thellier results will give less scatter than 140 microwave approach, as the duration of each microwave step is $c a .10$ seconds (Hill and 141 Shaw, 1999). Böhnel et al. (2003), though using microwave technique on a nearby profile, 142 provided PI mean results with similar dispersion as commonly obtained in Thellier. These 143 two points most likely rule out the effect of cooling rate as a major cause of intensity variation 144 acquired from Xitle volcano. 
145 In order to demonstrate the PI mean and scatter in each study and to illustrate the consistency

146 between different studies, we plot the PI data at specimen level on Figure 2. They are 214

147 data points [211 derived from Thellier and microwave and 3 from Shaw method] considered

148 acceptable by the author(s) of each work. As Figure 2 illustrates, the data from each study is

149 highly scattered and the whole data are inconsistent as well. We note that the PI-dispersion

150 of these studies cannot be compared as the number of data is not equal: half of data were

151 obtained by Böhnel et al. (1997) and Alva-Valdivia et al. (2005) while Urrutia-Fucugauchi

152 (1996) and Gonzalez et al. (1997) provided only 3 PI data points using Shaw technique. Using

153 all data, we calculate Xitle PI mean at $64.1 \mu \mathrm{T}$ (Fig. 2) and the 95\% standard deviation $(\sigma)$ is

$15411 \mu \mathrm{T}, c a .18 \%$ of the mean. Since the number of data is generously available and meet the

155 suggestion of Biggin et al. (2003) that PI mean value of any lava flow should be based on as

156 many samples as possible (at least five). Apparently this dispersion could be related to,

157 among others, some problems in the experimental PI methods (especially those applied long

158 time ago). We evaluate previous 211 Thellier and microwave - derived PI data in terms of

159 recently proposed reliability standards (e.g. Tauxe and Staudigel 2004; Chauvin et al., 2005;

160 Paterson et al., 2014). There are some other problems that could be seriously responsible for

161 such dispersion, including alteration of the ferromagnetic particles, cooling rate effect, and

162 presence of local magnetic field effects. These effects will not be addressed here.

163 Besides the low number of provided data, the two studies that used Shaw experiment

164 (Urrutia-Fucugauchi, 1996; Gonzalez et al.,1997) cannot be considered reliable as they did 165 not perform alteration tests (e.g. Tsunakawa and Shaw, 1994). In Thellier experiments, 166 samples are heated up gradually from low (e.g. $100{ }^{\circ} \mathrm{C}$ ) to high temperature (commonly 167 below curie point) and the natural remanent magnetization (NRM) is consecutively replaced 
168 by laboratory induced thermal remanent magnetization (TRM), in a known laboratory field.

169 This must be done with some alteration checks (Coe et al., 1978) in order to ensure that no

170 alteration occurred during repeated heating. Laboratory procedure of microwave method is

171 the same as Thellier but instead of heating in a conventional oven, samples are demagnetized

172 by exposure to high-frequency microwave (Walton et al., 1993). It has been proved by Hill

173 et al. (2002) that microwave demagnetization is equivalent to thermal counterparts implying

174 that sample's NRM is replaced by a laboratory induced TRM, for further details we refer to

175 the work of Hill and Shaw (2000) and Böhnel et al. (2003). Due to similarity in experimental

176 approaches, we have set for PI data derived from Thellier and microwave the same criteria

177 set, which are:

178 1) Treated sample must have been checked for thermal alteration during heating by means of

179 the pTRM check criterions ( $\delta \mathrm{CK}$ and/or $\delta$ pal);

180 2) The stability of the sample's NRM directions during the experiments must have been 181 evaluated by one or all next parameters: MADanc, $\alpha$, or DANG;

182 3) Following Biggin et al. (2003) suggestion, at least 5 specimens must have been used to 183 compute lava flow mean intensity with $\sigma \leq 10 \mu \mathrm{T}$ or $\leq 20 \%$ of the mean.

184 Applying these criteria set, we found that data presented in the work of Nagata et al. (1965), 185 Urrutia-Fucugauchi (1996), Gonzalez et al. (1997), Böhnel et al. (1997), Morales et al. (2001) 186 do not satisfy the mentioned criteria (Fig. 2). On the other hand, studies of Böhnel et al. 187 (2003), Alva Valdivia (2005), Morales et al. (2006), and Mahgoub et al. (2019) are reliable. 188 We calculate the Xitle mean PI from the 134 data considered as reliable data at $62.0 \mu \mathrm{T}$ with $189 \sigma$ of $9.3 \mu \mathrm{T}$ (see Fig. 2). This mean value is slightly below the mean calculated from all data 
190 and the error is also reduced, however statistically they are indistinguishable at the $95 \%$

191 confidence limit.

192 4. Methods

193 Rock magnetic experiments represented by the susceptibility versus temperature $(k-\mathrm{T})$

194 analyses and hysteresis measurements were done on 2-3 samples from each sampled profile

195 in order to check the magnetic variability in both horizontal and vertical directions.

196 Alternating field (AFD) and thermal demagnetization (THD) were measured in all the

197 samples of each profile. $k$-T curves were carried out up to $\sim 700^{\circ} \mathrm{C}$ with a Bartington-MS2

198 susceptibility-meter coupled with the furnace XXXX (????), and the mean Curie temperature

199 (Tc) were defined as the inflection point after peaks in $k$. We evaluate the thermal alteration

200 that could occur during the laboratory heating by calculating a reversibility

201 parameter: $R P \%=\frac{k h-k c}{k h} * 100$; where $k$ h and $k \mathrm{c}$ represent values of $k$ at heating and cooling

202 curves at $100^{\circ} \mathrm{C}$, respectively $\left(\right.$ reference $\left.? ?^{\circ}\right)$. Zero RP\% indicates that the heated specimen

203 does not experience alteration. Hysteresis analyses were executed with the AGFM

204 (Alternating Gradient Force Magnetometer) for which samples weighting 5 to $40 \mathrm{mg}$ were

205 used. The hysteresis parameters (saturation magnetization (Ms); saturation remanent

206 magnetization (Mrs); coercive force (Hc); and coercivity of remanence (Hcr)) lead to have

207 an idea of the magnetic domain state of the magnetic carriers, Day diagram (Day et al., 1977).

208 AFD measurements were progressively applied from 5 to $100 \mathrm{mT}$ with an AGICO LDA-3

209 equipment. Also, THD was carried out with ASC TD-48 thermal demagnetizer model in

210 every $50{ }^{\circ} \mathrm{C}$ from 100 to $500{ }^{\circ} \mathrm{C}$ and then from 530 to $600{ }^{\circ} \mathrm{C}$ in $30{ }^{\circ} \mathrm{C}$ step. From the

211 demagnetization measurements, we have calculated the median destructive field (MDF) and

212 median destructive temperature (MDT), which defined how the alternating field and 
213 temperature values of the NRM loses half of its value.

214 PI experiments were estimated with the multispecimen method (Dekkers and Böhnel, 2006)

215 through which specimens are heated only once in different DC fields directed, independently,

216 parallel to the their NRM. The original protocol includes two steps: $\mathrm{m} 0$ and $\mathrm{m} 1$. Thereafter,

217 two additional steps ( $\mathrm{m} 2$ and $\mathrm{m} 3$ ) were proposed by Fabian and Leonhardt (2010) in order to

218 correct for the domain state effect, and one more step (m4), where we repeat $\mathrm{m} 1$, is proposed

219 to check for any mineralogical alteration occurred during the experiment. In this study, 37

220 specimens were taken from all profiles to conduct the original (MSP-DB; referred to Dekkers

221 and Böhnel) and corrected (MSP-DSC; referred to domain state correction) protocols.

222 Heatings were carried out by use of a new infra-red-heating ultra-fast furnace developed and

223 available in the Geosciences Montpellier laboratory, called 'FUReMAG'. The heating-

224 cooling time in the FUReMAG furnace lasts 45 minutes. Based on the $k$-T curves and THD

225 results, the set-temperature will be selected so as to ensure unblocking sufficient portion of

226 NRM. Thus, we can get steeped linear fit with small confidence limit (Monster et al., 2015a),

227 and also magneto-mineralogical alteration can be avoided. To eliminate unwanted viscous

228 component in the NRM, the specimens were heated to $100^{\circ} \mathrm{C}$ and cooled to room temperature

229 in zero field, before the NRM measurement (m0 step). To be consistent with this pre-

230 treatment, the low temperature $\operatorname{pTRM}\left[100^{\circ} \mathrm{C}\right.$, Troom $]$ was removed in the same way after

231 each pTRM acquisition ( $\mathrm{m} 1, \mathrm{~m} 2, \mathrm{~m} 3$, and $\mathrm{m} 4$ steps) involved in the MSP-DSC protocol. The

232 magnetic remanence was measured with a cryogenic magnetometer $(2 \mathrm{G})$.

233 5. Results

$234 \quad 5.1$ Magnetic properties

235 The $k$-T curves (Figs.4a) indicate the presence of several magnetic minerals in distinct 236 proportion. The Tc range from 540 to $>600{ }^{\circ} \mathrm{C}$ and $\mathrm{RP} \%$ from 4 to $80 \%$, suggesting the 
237 presence of magnetite (Mag), Ti-poor titanomagnetite (Ti-poor TMag), and hematite with 238 varied reversibility degrees. In all studied samples, $k$ value decrease after heating, indicating 239 that enclosed magnetic minerals have been oxidized. We found that both Tc and RP\% do not 240 have any systematic behavior vertically or horizontally, but we can mention that HT and HM 241 profiles have moderate to good reversibility, respectively. Specimens of HB gave dissimilar 242 results and thus no clear conclusion can be outlined.

243 Hysteresis analyses show that all investigated samples are located in the range of PSD field 244 (Fig. 4b), which may suggest presence of a mixture of SD and MD particles in different 245 percentages. HT samples are located close together in the Day plot while those of HM and 246 HB did not show similar consistency. We deduced from these observations that HT profile 247 has a small homogenous PSD particles while, on the other hand, the middle and bottom 248 profiles have somewhat larger ferromagnetic particles of widespread type and/or size. 249 Apparently, few samples are provided this explanation and thus more samples would lead to 250 track better the domain state along vertical and horizontal profiles. However, the recent 251 findings of Roberts et al. (2018) should be mentioned where they find out that domain state 252 of a sample cannot be grasped simply from the Day plot as the hysteresis parameters are 253 based on several variables (Roberts et al., 2018).

254 Intensity-decay curves along the three horizontal profiles results from AFD measurements 255 (Fig. 4c) do not show any systematic behavior (as in previous experiments), and the MDF 256 ranges from 5 to $55 \mathrm{mT}$ thus indicating the presence of varying magnetic grain composition 257 along the three sampled profiles. The THD data (Fig. 4d) showed the appearance of common 258 Tc point of magnetite $\left(c a .560^{\circ} \mathrm{C}\right)$ with small contribution from hematite, thus in agreement 259 with $k$-T curves. The MDTs are from 300 to $500{ }^{\circ} \mathrm{C}$ with a tendency of HB's samples (58, 
59 and 64) to have lower MDT in comparison to HT and HM. This tendency could be

261 attributed to the presence of different Ti contents (as they have low unblocking temperature

262 spectra) or to large magnetic minerals size in the HB samples.

263 To sum up, magnetic experiments showed that rock from the sampled profiles, although of

264 limited vertical and horizontal spread, have wide range of type composition and size of the

265 enclosed magnetic minerals.

\section{$266 \quad 5.2$ MSP-DSC results}

267 The multispecimen data corrected for domain state (MSP-DSC) were analyzed with MSP-

268 Tool (Monster et al., 2015) software. The set-temperature throughout the experiments is $269400^{\circ} \mathrm{C}$ and applied DC fields range from 10 to $80 \mu \mathrm{T}$. The domain state proxy ( $\alpha$-parameter)

270 was set to 0.5, as proposed by Fabian and Leonhardt (2010). Credibility of the MSP results

271 were checked by three parameters: thermal-induced alteration $|\varepsilon a l t|$ parameter (Fabian $\&$

272 Leonhardt 2010; Monster et al. 2015b); the maximum allowed angle ( $\theta)$ between the isolated

273 NRM and acquired pTRM; and the intersection parameter ( $\Delta \mathrm{b})$ (Monster et al., 2015b), which

274 tests whether the linear fit regression line intersects the y-axis at the theoretically predicted

275 value of -1 . In order to confirm the obtained and only reliable results, we have set $|\varepsilon a l t| \leq$ $2765 \%, \theta$ must be less than $10^{\circ}$, and a threshold value of $\Delta \mathrm{b}$ is \pm 0.1 . In the MSP-Tool software,

277 the bootstrap statistics were applied to calculate the mean and 95\% confidence intervals.

278 Technically, successful MSP experiments were obtained from profiles V and HT, while both

$279 \mathrm{HM}$ and HB failed to give reliable estimates as their calt parameter exceeded the defined

280 limit. In $\mathrm{V}$, three specimens out of nine were rejected (Fig. 5a) as they have altered during

281 the MSP run. The remaining six met the criteria limit defined above and thus a domain state 282 corrected PI mean of $62.9 \pm 2.6 \mu T$ was obtained for the vertical profile. The HT gave 
successful MSP experiment in eight out of ten specimens (Fig 5b), with PI value of 58.6 $\mu T$,

284 after DSC procedure. We note here that $95 \%$ confidence interval in HT $(+6.5 /-6.3 \mu \mathrm{T})$ is

285 almost double the value of the confidence interval in V. Obviously, this high scatter is

286 reasoned by the noticeable nonlinearity behavior, in the last field steps (Fig. 5b), between the

287 TRM and applied magnetic field. This non-ideal behavior can be attributed to presence of

288 large ferromagnetic particles, which can reduce the efficiency of linearity law (Selkin et al.,

289 2007). Regarding to HM, only one specimen out of nine passed the alteration limit (Fig. 5c),

290 indicating that most of the middle-zone specimens are susceptible to alteration. In addition,

291 the last data points are not aligned linearly which probably point to the dominance of MD

292 particles. Therefore, no reliable results were obtained from this profile.

293 We have neglected the criteria limits to obtain reliable results without regard to data quality,

294 just to see the impact of the sample position in vertical profile on the PI results. A MSP-DSC

295 value of $67.2 \mu T$ was obtained, this is demonstrated in the supplementary Figure S1. Three

296 accepted data out of nine (33\% success rate) was found along HB profile (Fig. 5d) and thus

297 no meaningful estimate could be obtained. As in HM, if we neglect the criteria set parameters

298 (Fig. S2), a value of $60.8 \mu T$ is calculated for HB profile.

299 From the above results, it is obvious that only the vertical and upper horizontal profiles gave

300 reliable results that meet the proposed criteria limits. Therefore, combining all accepted

301 specimens from V and HT enables us to assign Xitle-mean PI (Fig. 6a) at 60.5 (+4.0/-4.1)

$302 \mu T$. Including all the 18 specimens of HM and HB (Fig. 6b) gives, unexpectedly, a mean

303 value of $63.8(+5.2 /-5.8) \mu \mathrm{T}$, which considering the uncertainty limits, is indistinguishable

304 from the mean value calculated from only reliable results. This consistency may denote that

305 the current conditions set for accepting the MSP results (calt and $\Delta b$ ) are ineffective. Such 
explanation, however, cannot be confirmed in this study, as the actual intensity value during

307 Xitle eruption time (370 AD) is unknown. But, we can deduce that obtaining reliable MSP

308 results for a certain lava unit could be achieved by taking many specimens as possible from

309 different parts within the lava flow. However, these approaches will costs effort and time.

\section{6. Discussion}

311 Three horizontal profiles were sampled from Xitle in three levels from bottom to top in order

312 to discuss horizontal variations of paleointensity. Horizontal characteristics along these

313 profiles were investigated as well through sampling one vertical profile of $c a .4 .5 \mathrm{~m}$

314 thickness. Rock magnetic experiments were completed to infer the type and size of the

315 ferromagnetic minerals and their thermal stability. It must be mentioned that the number of

316 present samples that have undergone magnetic experiments and MSP run are few and uneven,

317 and thus the relationship between magnetic properties and paleointensity behavior along

318 lava's profile may not be clear. However is not the main focus of this study, as we here try

319 to enhance the PI estimates of Xitle by evaluating previous data and conducting a new MSP

320 experiment. Completing this, we can provide an average value with low confidence limit,

321 through combining present PI results with reliable results obtained from previous studies.

322 Despite the limited number of data, we can give a general overview of the impact of lava

323 position and its physical and magnetic properties on the MSP results. Currently, few studies

324 have addressed the relation between rock magnetic properties and lava flow thickness. Some

325 studies (Coe et al., NATURE, 1995; Rolph, 1997; Hill and Shaw, 2000; Vérard et al., 2012)

326 have discussed this relation on thin lava flows, thickness $<2 \mathrm{~m}$, some others extended these

327 studies to thicker lavas of 6m long (Böhnel et al., 1997; de Groot et al., 2014), and up to

328 several tens of meters (e.g. Wilson et al., 1968; Audunssen et al., 1992). Findings from these 
studies indicate an effect of the sampling location on the magnetic properties. Lava thickness

330 reflects different cooling history, the top and bottom parts cooled faster than the central part

331 of the flow. These variations in cooling time govern the size of the ferromagnetic crystals

332 and their oxidations states. The top part of the lava flows may produce smaller ferromagnetic

333 sensus lato particles with lower oxidation state in comparison to those formed in the middle

334 of the flow (see for example Böhnel et al., 1997; de Groot et al., 2014).

335 Böhnel et al. (1997) showed detailed results of Xitle's rock magnetic properties (i.e. Tc, 336 magnetic susceptibility, hysteresis parameters, and coercivities) and PIs along a vertical

337 profile of $6 \mathrm{~m}$ thickness. Results indicate that, unlike magnetic properties, the PIs seem to 338 have a systematic behavior with tendency of middle flow samples to give larger PI variations

339 in comparison to the top and bottom samples. Despite the detailed study, they did not find 340 meaningful relation between PI variations and physical and magnetic properties. Our 341 sampled profile spaced only $(0.96 \mathrm{~km})$ from Böhnel et al. (1997) profile, implying that they 342 shared almost the same cooling history. The rock-magnetic experiments done in this study 343 showed that Ti-poor TMt and/or Mt is the dominant ferromagnetic mineral(s) and few 344 hematite is present, showed from $k$-T curves (Fig. 4a). These minerals are located broadly on 345 the PSD size with wide range of MDF ( from ca. 5 to $56 \mathrm{mT}$ ). From top to bottom (V), and 346 along each horizontal profile (HT, HM, HB), we do not find any systematic changes on the 347 magnetic properties although of the, above mentioned, differences in cooling times. Although 348 the magnetic parameters obtained in this study varied (e.g. RP\%, MDF and MDT) 349 horizontally, we consider that they do not reflect true magnetic properties changes, as the 350 cooling time and content of the cooled lava on such a small scale $(1.5 \mathrm{~m})$ are seemingly 351 constant, at least in comparison to vertical direction. This discrepancy in magnetic data could 
352 be attributed to the limited number of rock magnetic experiments carried out. In conclusion, 353 there is not a direct connection found between lava thickness and its $1.5 \mathrm{~m}$ lateral extent with 354 the magnetic properties.

355 Now, we discuss the influence of cooling time on the MSP results. Our contributed results 356 show that the topmost horizontal profile and the vertical profile have yielded successful MSP357 DSC PI determinations from the 14 selected samples out of 19 available (74\% success rate).

358 On the hand, samples from central and bottom parts of the flow do not give satisfactory MSP 359 results, as they have exceeded the limits of criteria set designed following Monster et al.

360 (2015). Apparently, getting differential MSP results and success rate from over a flow section 361 of $4.5 \mathrm{~m}$ thickness can be directly related to the cooling time of this flow. It means that top 362 part of the Xitle flow is appropriate for conducting MSP experiments as it has cooled faster 363 than underlying horizontal sections. Moreover, conducting the experiment vertically does 364 give almost the same results given from HT profile (Fig. 5a and b), which could indicate that 365 the effect of cooling time on MSP results may be insignificant or even disappeared if samples 366 are taken vertically. This explanation is based on a few number of samples and more studies 367 are needed to emphasize it. From these notes, we recommend sampling a lava flow 368 horizontally from its top part when the lava flow is notovered by a younger flow, and 369 vertically in order to give a reliable MSP estimates.

\section{7. Conclusions}

373 The rock magnetic properties indicate that the main magnetic minerals are Ti-poor 374 titanomagnetite with small contribution from hematite of PSD carriers accomplish the quality 
375 criterion to be able for paleointensity experiments.

376 Successful MSP-DSC experiments were obtained from profiles V and HT, while both HM 377 and HB failed to give reliable estimates. Results obtained in this study from 14 accepted 378 specimens of HT and V profiles give an average mean for Xitle at $60.5(+4.0 /-4.1) \mu T$. This 379 value constrains greatly the dispersion and we consider it should substitute the value for the 380 Xitle from the database used by models in order to do more precise the secular variation 381 curve used for the dating of geologic and archeomagnetic materials of this period.

382 This mean value is consistent with the mean $(62.0 \pm 9.3 \mu T)$ calculated from 134 filtered 383 Thellier \& microwave old PI data. The whole PI mean value for Xitle, using a combined 384 formula (Higgins and Green, 2011) gives $61.9 \pm 9 \mu \mathrm{T}$. This mean value is calculated from 385 high quality data provided from three different PI methods, therefore most likely represents 386 the intensity value for Central Mexico at $c a .370$ AD.

\section{Acknowledgments}

390 We appreciate the financial support to L. M. Alva-Valdivia from PAPIIT-DGAPA-UNAM 391 IN113117 and ANR-CONACyT (France-Mexico) 273564, research projects. AN Mahgoub 392 acknowledged the financial support of the Universidad Nacional Autónoma de México393 postdoctoral fellowship. M. A. Bravo-Ayala was partly financially supported by a 394 scholarship from CONACyT and a Research Grant from Dr. P. Camps and Dr. T. Poidrás 395 whom allowed the use of the Paleomagnetic laboratory of Geoscience University of 396 Montpellier, France. Thanks to J. A. González Rangel for the support on the Mexican 397 Paleomagnetic laboratory experiments. 


\section{References}

Aitken, M., Allsop, A., Bussell, G., Winter, M., 1988. Determination of the intensity of the Earth's magnetic field during archaeological times: Reliability of the Thellier technique. Rev. Geophys. 26 (1), 3-12.

Alva-Valdivia, L., 2005, Comprehensive paleomagnetic study of a succession of Holocene olivine-basalt flow: Xitle Volcano (Mexico) revisited, Earth Planets Space, Vol. 57, pp. 869-853.

Audunssen, H., S. Levi, and F. Hodges (1992), Magnetic property zonation in a thick lava

Biggin, A.J., Steinberger, B., Aubert, J., Suttie, N., Holme, R., Torsvik, T.H., van der Meer, D.G., van Hinsbergen, D.J.J. (2012) Possible links between long-term geomagnetic 644 variations and whole-mantle convection processes. Nat Geosci 5:526-533

Biggin, A.J., Böhnel, H.N. \& Zuniga, F.R., 2003. How many paleointensity determinations are required from a single lava flow to constitute a reliable average? Geophys. Res. Lett., 30(11).

Böhnel, H., Morales, J., Caballero, C., Alva, L., McIntosh, G., González, S. y Sherwood, J., 1997, Variation of rock magnetic parameters and paleointensities over a single holocene lava flow, J. Geomag. Geoelectr., 49, 523 - 542.

Böhnel, H., E. Herrero-Bervera, and M. J. Dekkers (2011), Paleointensities of the Hawaii 1955 and 1960 Lava Flows: Further Validation of the Multi-specimen Method, pp. 195-211, Springer, Dordrecht, Netherlands.

Coe RS, Grommé S, Mankinen EA (1978) Geomagnetic paleointensities from radiocarbon dated lava flows on Hawaii and the question of the Pacific nondipole low. J Geophys 
432 Cromwell, G., Tauxe, L., Staudigel, H., Ron, H., 2015. PI estimates from historic and 433 modern Hawaiian lava flows using glassy basalt as a primary source material. Phys. Earth Planet. Inter.241, 44-56.

de Groot, L. V., T. A. T. Mullender, and M. J. Dekkers (2013), An evaluation of the influence of the experimental cooling rate along with other thermomagnetic effects to explain anomalously low palaeointensities obtained for historic lavas of Mt Etna (Italy), Geophys. J. Int., 193(3), 1198-1215, doi:10.1093/gji/ggt065.

de Groot, L.V., Dekkers, M.J., Visscher, M., ter Maat, G.W., 2014. Magnetic properties and paleointensities as function of depth in a Hawaiian lava flow. Geochem. Geophys. Geosyst.15. http://dx.doi.org/10.1002/2013GC005094.

Day, R., Fuller, M., Schmidt, V.A., 1977. Hysteresis properties of titanomagnetites: grain size and compositional dependence. Phys. Earth Planet. Inter. 13, 260-267.

Dekkers, M.J., Böhnel, H.N., 2006. Reliable absolute palaeointensities independent of magnetic domain state. Earth Planet. Sci. Lett. 284, 508-517.

Dunlop, D.J., 2002. Theory and application of the Day plot (Mrs/Ms versus Hcr/Hc) 1. Theoretical curves and tests using titanomagnetite data. J. Geophys. Res 107(B3) 2056. doi:10.1029/2001JB000486.

Fabian, K., Leonhardt, R., 2010. Multiple-specimen absolute PI determination: An optimal protocol including pTRM normalization, domain-state correction, and alteration test. Earth Planet. Sci. Lett. 297, 84-94.

Gonzalez S, Sherwood GJ, Boehnel H, Schnepp E (1997), Paleosecular variation in central Mexico over the last 30,000 years: The record from lavas. Geophys J Int 130: $201-219$.

González, S., Pastrana, A., Siebe, C., Duller, G., 2000. Timing of the prehistoric eruption of Xitle volcano and the abandonment of Cuicuilco pyramid, southern Basin of Mexico. Geol. Soc. London Sp. Pub. 171, 205-224. https://doi.org/10.1144/GSL.SP.2000.171.01.17.

Grappone, J.M., Biggin, A.J., Hill. M.J., 2019: Solving the mystery of the 1960 Hawaiian lava flow: implications for estimating Earth's magnetic field. Geophys. J. Int., 218, 1796-1806. 
462

463

464

465

466

467

468

469

470

471

472

473

474

475

476

477

478

479

480

481

482

483

484

485

486

487

488

489

490
Guilbaud, M.N., Siebe, C., Layer, P., Salinas, S., 2012. Reconstruction of the volcanic history of the Tacámbaro-Puruarán area (Michoacán, México) reveals high frequency of Holocene monogenetic eruptions. Bull. Volcanol. 74, 1187-1211.

Heizer, R.F., Bennyhoff, J.A., 1958. Archeological investigations of Cuicuilco, Valley of Mexico, 1957. Science 127, 232 \pm 233.

Higgins J and Green S. Cochrane Handbook for Systematic Reviews of Interventions Version 5.1.0. The Cochrane Collaboration, 2011, www.handbook.cochrane.org.

Hill, M. J., and J. Shaw (1999), Palaeointensity results for historic lavas from Mt Etna using microwave demagnetization/remagnetization in a modified Thellier-type experiment, Geophys. J. Int., 139(2), 583-590

Hill, M. J., and J. Shaw (2000), Magnetic field intensity study of the 1960 Kilauea lava flow, Hawaii, using the microwave PI technique, Geophys. J. Int., 142, 487-504.

Luhr, J.F., Simkin, T., 1993. Paricutin: The Volcano Born in a Mexican Cornfield. Geoscience Press (427 p).

Mahgoub, A.N., Juárez-Arriaga, E., Böhnel, H., Manzanilla, L.R., Cyphers, A., 2019. Refined 3600 years palaeointensity curve for Mexico. Phys. Earth Planet. Inter. Accepted.

Morales, J., Alva-Valdivia, L., Goguitchaichvili, A. y Urrutia-Fucugauchi, J., 2006, Cooling rate corrected paleointensities from the Xitle lava flow: Evaluation of within-site scatter for single spot-reading cooling units, Earth Planets Space, Vol. 58, pp. 13411347.

Morales, J., Goguitchaichvili, A. y Urrutia-Fucugauchi, J., 2001, A rock-magnetic and PI study of some Mexican volcanic lava flows during the Latest Pleistocene to the Holocene, Earth Planets Space, Vol. 53, pp. 893-902.

Monster, M.W.L., de Groot, L.V., Biggin, A.J., Dekkers, M.J., 2015a. The performance of various PI techniques as a function of rock magnetic behaviour - a case study for La Palma. Phys. Earth Planet. Inter. 242, 36-49. http://dx.doi.org/10.1016/ j.pepi.2015.03.004 
Monster, M.W.L., de Groot, L.V., Dekkers, M.J., 2015b. MSP-tool: a VBA-based software tool for the analysis of multispecimen PI data. Front. Earth Sci. 3, 86. http://dx.doi.org/10.3389/feart.2015.00086.

Nagata, T., Kobayashi, K., Schwarz, E.J., 1965. Archaeomagnetic intensity studies of South and Central America. J. Geomagnetism Geoelectricity, 17, 399-405, https://doi.org/10.5636/jgg.17.399

Nilsson A, Holme R, Korte M, Suttie N, Hill M (2014) Reconstructing Holocene geomagnetic field variation: New methods, models and implications. Geophys J Int 198(1):229-248

Paterson GA, Tauxe L, Biggin AJ, Shaar R, Jonestrask LC (2014) On improving the 843 selection of Thellier-type paleointensity data. Geochem Geophys Geosyst 15(4): 1180-844 1192

Roberts, A.P., Tauxe, L., Heslop, D., Zhao, X., Jiang, Z., 2018. A critical appraisal of the 520 Day diagram. J. Geophys. Res. 123, 2618-2644. https://doi.org/10.1002/2017JB015247. 
Selkin, P. A., J. S. Gee, and L. Tauxe (2007), Nonlinear thermoremanence acquisition and implications for PI data, Earth Planet. Sci. Lett., 256, 81-89, doi:10.1016/j.eps1.2007.01.017.

Siebe, C., 2000. Age and archaeological implications of Xitle volcano, southwestern Basin of Mexico-City. J. Volcanol. Geotherm. Res. 104, 45-64. https://doi.org/10.1016/S0377-0273(00)00199-2.

Shaw, J., 1974, A new method of determining the magnitude of the paleomagnetic field application to 5 historic lavas and five archeological samples. Geophysical Journal of the Royal Astronomical Society 39: 133-141. doi: 10.1111/j.1365246X.1974.tb05443.x.

Stacey, F.D. \& Banerjee, S.K., 1974. The Physical Principles of Rock Magnetism, Elsevier, Amsterdam.

Tauxe, L., T. Pick, and Y. Kok (1995), Relative PI in sediments: A pseudo-Thellier approach, Geophys. Res. Lett., 22(21), 2885-2888.

Thellier, E. \& Thellier, O., 1959. Sur l'intensité du champ magnétique terrestre dans le passé historique et géologique, Ann Géophys., 15, 285-376.

Tauxe, L., Staudigel, H., 2004. Strength of the geomagnetic field in the Cretaceous Normal Superchron: new data from submarine basaltic glass of the Troodos Ophiolite. Geochem. Geophys. Geosyst. 5 (Q02H06).

Tsunakawa, H., Shaw, J., 1994. The Shaw method of PI determinations and its application to recent volcanic rocks. Geophys. J. Int. 118, 781-787.

Urrutia Fucugauchi, J., 1996. Palaeomagnetic study of the Xitle- Pedregal de San Angel lava flow, southern Basin of Mexico. Physics of the Earth and Planetary Interiors 97, 177196.

Verard, C., R. Leonhardt, and M. Winklhofer (2012), Variations of magnetic properties in thin lava flow profiles: Implications for the recording of the Laschamp Excursion, Phys. Earth Planet. Inter., 200-201, 10-27, doi:10.1016/j.pepi.2012.03.012.

Walton, D., Share, J.A., Rolph, T.C. \& Shaw, J., 1993. Microwave magnetisation, Geophys. Res. Lett., 20, 109-111. 
Wilson, R. L., S. E. Haggerty, and N. D. Watkins (1968), Variation of palaeomagnetic stability and other parameters in a vertical traverse of a single Icelandic lava, Geophys. J. R. Astron. Soc., 16, 79-96.

Yamamoto,Y., Tsunakawa,H.\&Shibuya, H., 2003. Palaeointensity study of the Hawaiian 1960 lava: implications for possible causes of erroneously high intensities, Geophys. J. Int., 153(1), 263-276.

\section{List of Figures}

Figure 1. Distribution of Xitle lava flows I to VI, with the location of the sampling site and the Cuicuilco archeological site. Modified after Delgado et al. (1998).

Figure 2. Evaluation of previous PI data published for Xitle. The closed and open circles represent reliable and unreliable data based on a set of selection criteria designed in this study (see section 2). The dotted line and shaded area is the Xitle mean paleointensity value and 95\% standard deviation, calculated from only reliable data. the $\mathrm{x}$-axis represent different studies that were done on Xitle.

for abbreviations: Nag-65 is Nagata et al. (1965); UFT-96 is Urrutia-Fucugauchi (1996), from thellier experiment; UFS-96 is Urrutia-Fucugauchi (1996) from Shaw experiment; $B H$ 97 is Böhnel et al. (1997); GZT-97 is Gonzales et al. (1997) from thellier; GZS-97 is Gonzales et al. (1997) from Shaw; M-01 is Morales et al. (2001); BHT-03 is Böhnel et al. (2003) from thellier after re-analyzing data of Böhnel et al. (1997); BHMl-03 is Böhnel et al. (2003) from microwave done on lavas; BHMp-03 is Böhnel et al. (2003) from microwave done on potteries; LA-05 is Alva-Valdivia (2005); M-06 is Morales et al. (2006); and MG-19 is Mahgoub et al. (2019, accepted for publication).

Figure 3. Sampling profile. Lava flow with scale $(1 \mathrm{~m})$. Three zones are observed with the naked eye: the massive central zone and the upper zone that present abundant vesicles and lower with much less and tiny vesicles. The core numbers are shown in order to be compared with upcoming rock magnetic properties and paleointensities. 
584 Figure 4. Rock magnetic results done in this study: (a) susceptibility vs. temperature curves;

585 (b) Day plot (Day et al., 1977) with thresholds for single domain (SD), pseudo single domain 586 (PSD), and multidomain (MD) shown as straight grey lines. Dashed curved lines represent 587 the SD-MD theoretical mixing curves, after Dunlop (2002); (c) intensity decay curves 588 obtained after alternating field demagnetization; (d) intensity decay curves after thermal 589 demagnetization. Numbers in each panel diagram represent core sample, see Figure 3. 590 AHMED, LAS CURVAS EN 4A CASI NO SE VEN. Y EN 4C Y 4D EL EJE Y DEBE SER 591 NORMALIZED MAGNETIZATION.

592

593 Figure 5. Multispecimen results obtained from four sampled profiles, after domain state 594 correction (DSC). In each DSC protocol, the average alteration parameter (calt) and the 595 intersection criterion $(\Delta b)$ are demonstrated to judge the credibility of the given results. Note 596 that data were analyzed with MSP-Tool software (Monster et al., 2015b) where bootstrap 597 statistics were applied to calculate the mean (solid black line) and 95\% confidence interval 598 (dashed black lines lines). Black and orange circles represent those accepted and unaccepted 599 data, respectively, based on the criteria limit defined in the present study. (a and b) represent 600 accepted experiments done on profiles V and HT, as their specimens meet the designed 601 criteria limit, and (c and d) represent unaccepted experiments from profiles HM and HB and 602 thus no PI mean could be calculated from these two profiles.

603

604 Figure 6. (a) Xitle PI mean value calculated from only reliable experiments done on V and 605 HT profiles. (b) represents unreliable experiments (from profiles HM and HB), and the 606 bootstrap mean (solid black line) and 95\% confidence interval (dashed black lines lines) are 607 shown to compare the Pi results obtained from reliable (a) and unreliable (b) data. 


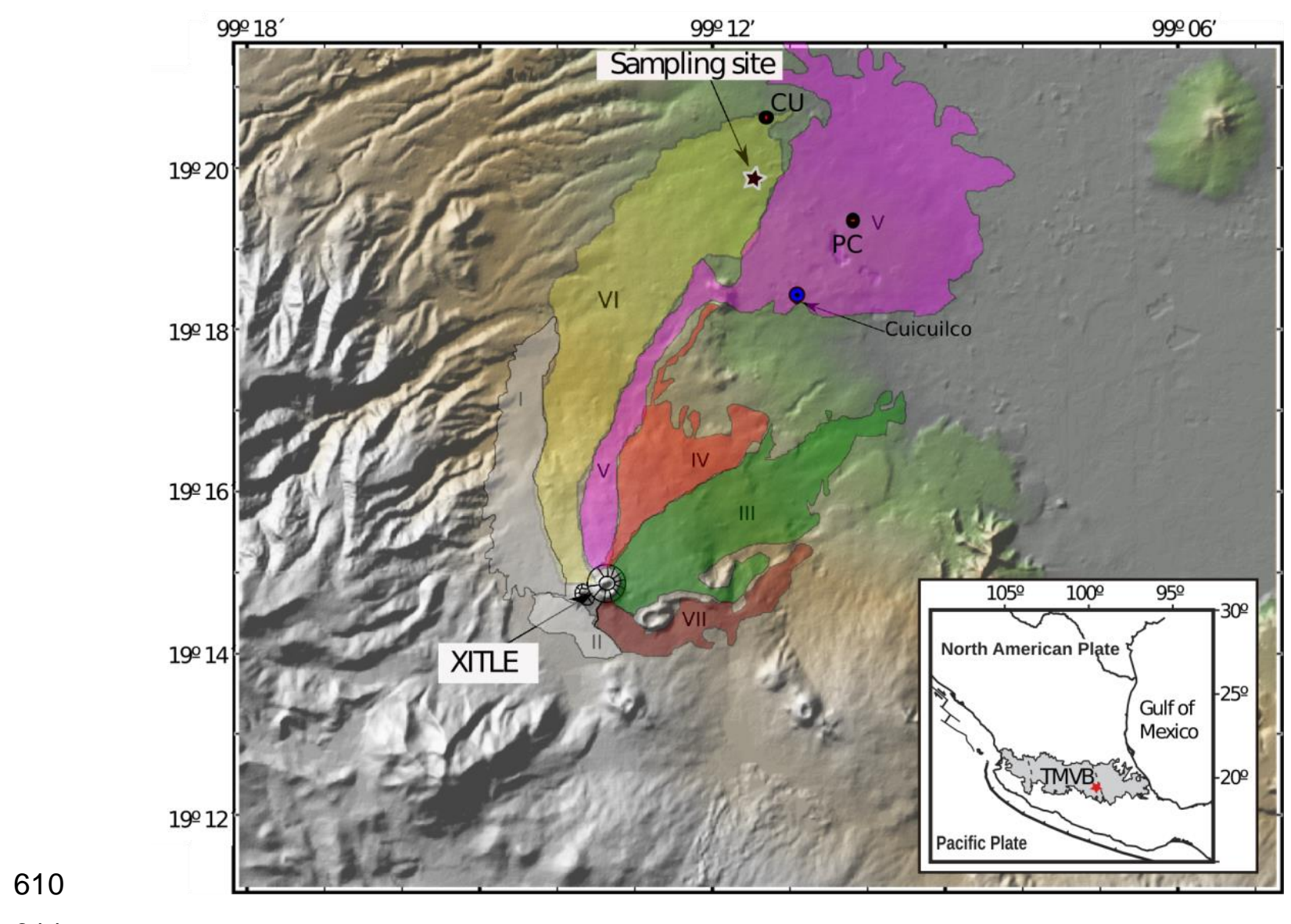

611

612 Figure 1. Distribution of Xitle lava flows I to VI, with location of the sampling site and

613 Cuicuilco archeological site. Modified after Delgado et al. (1998). WE ARE STILL 614 WORKING ON THIS FIGURE!

615

616

617

618

619 


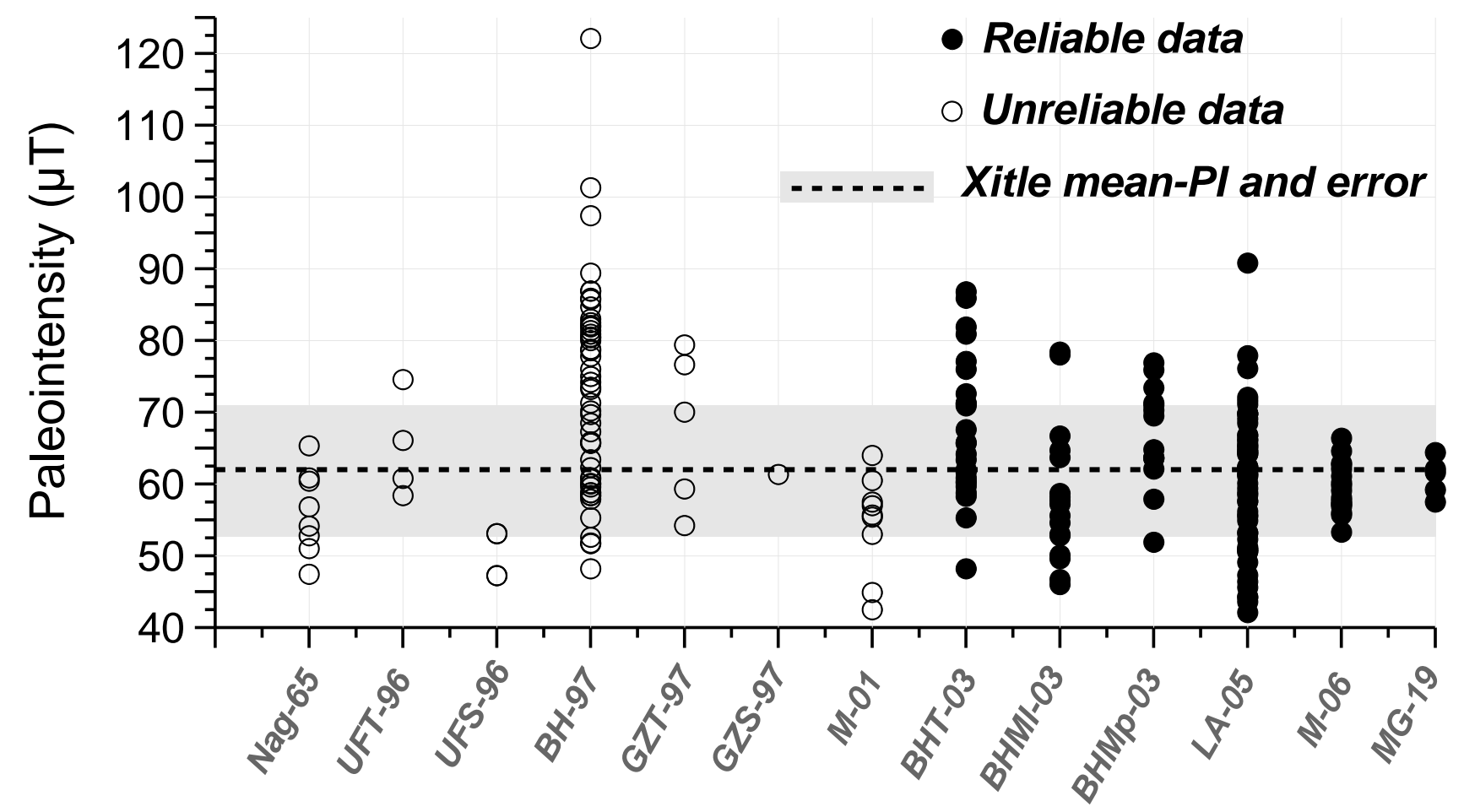

Figure 2. Evaluation of previous PI data published for Xitle. The closed and open circles represent reliable and unreliable data based on a set of selection criteria designed in this study (see section 2). The dotted line and shaded area is the Xitle mean paleointensity value and 95\% standard deviation, calculated from only reliable data. the $\mathrm{x}$-axis represent different 627 studies that were done on Xitle.

628 for abbreviations: Nag-65 is Nagata et al. (1965); UFT-96 is Urrutia-Fucugauchi (1996), 629 from thellier experiment; UFS-96 is Urrutia-Fucugauchi (1996) from Shaw experiment; $B H$ 63097 is Böhnel et al. (1997); GZT-97 is Gonzales et al. (1997) from thellier; GZS-97 is Gonzales 631 et al. (1997) from Shaw; M-01 is Morales et al. (2001); BHT-03 is Böhnel et al. (2003) from 632 thellier after re-analyzing data of Böhnel et al. (1997); BHMl-03 is Böhnel et al. (2003) from 633 microwave done on lavas; BHMp-03 is Böhnel et al. (2003) from microwave done on 634 potteries; $L A-05$ is Alva-Valdivia (2005); $M-06$ is Morales et al. (2006); and $M G-19$ is 635 Mahgoub et al. (2019, accepted for publication). 


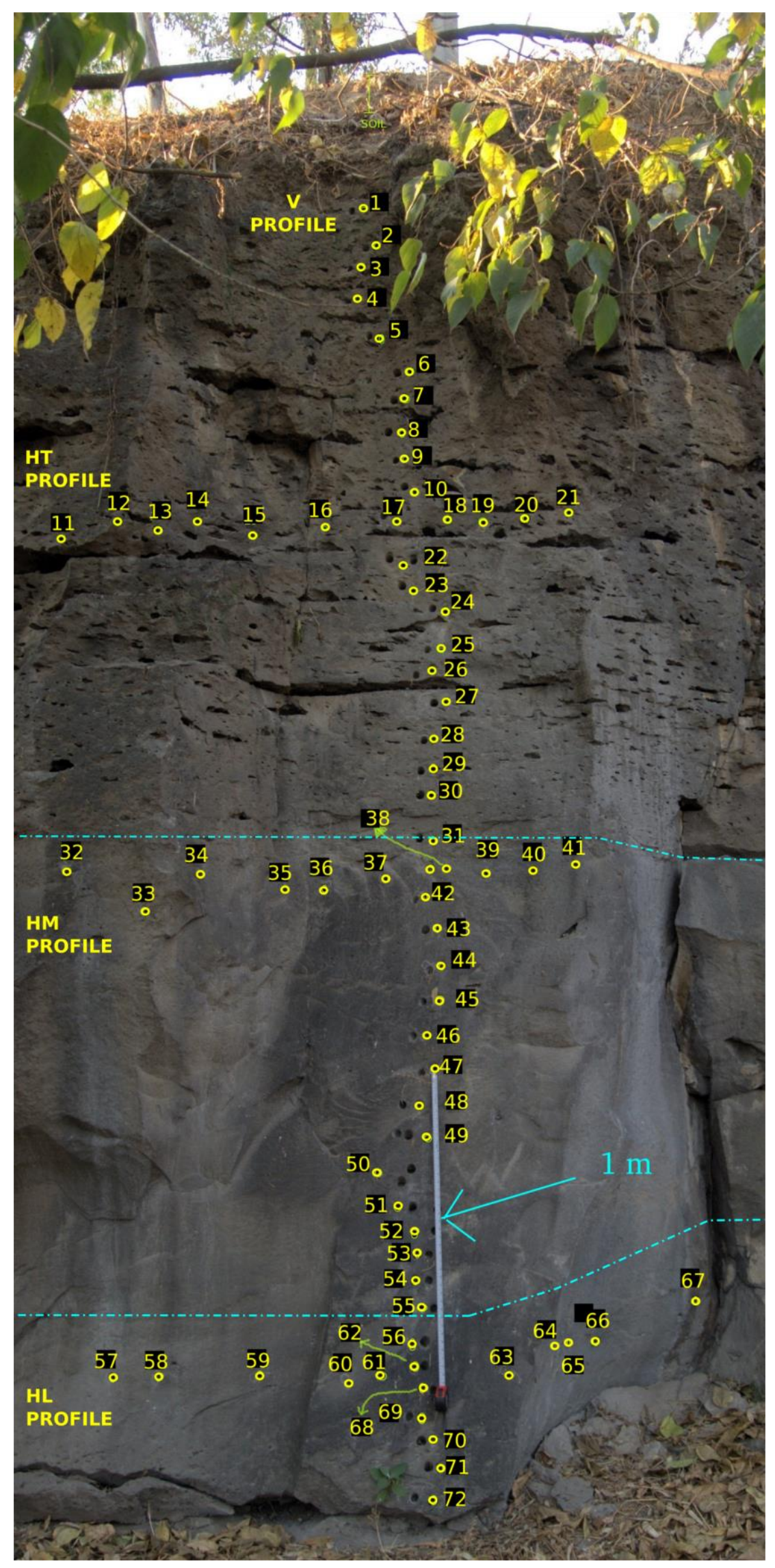


637 Figure 3. Sampling profile. Lava flow with scale $(1 \mathrm{~m})$. Three zones are observed with the 638 naked eye: the massive central zone and the upper and lower zones that present vesicles. The 639 core numbers are shown in order to be compared with upcoming rock magnetic properties 640 and paleointensities. 


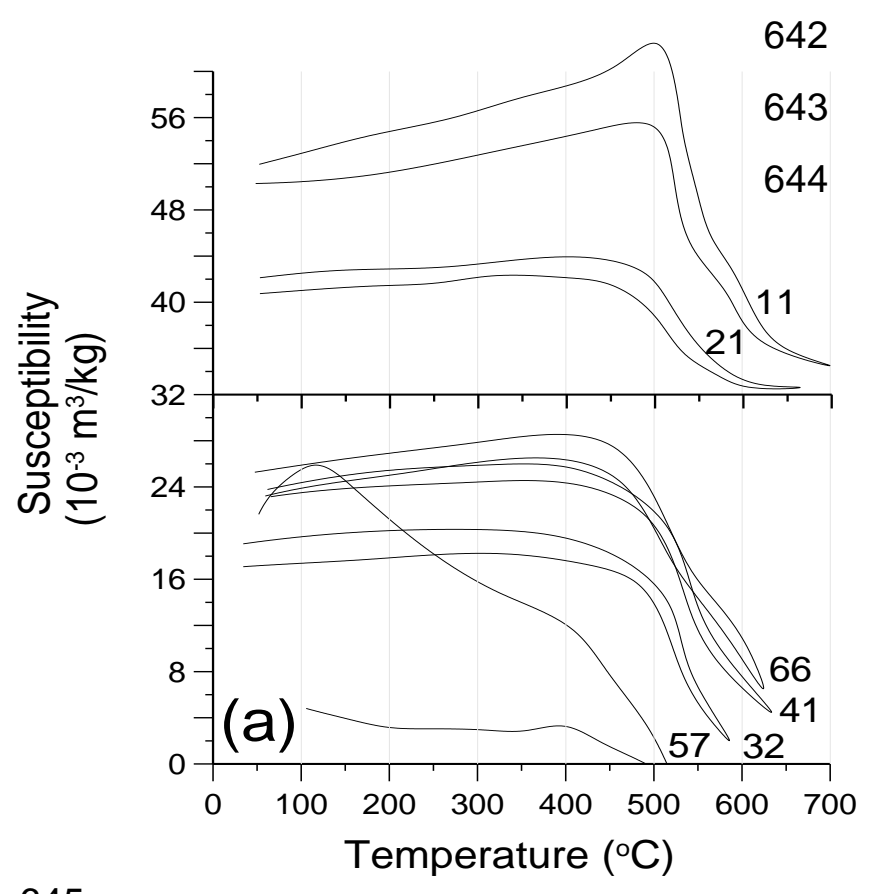

645
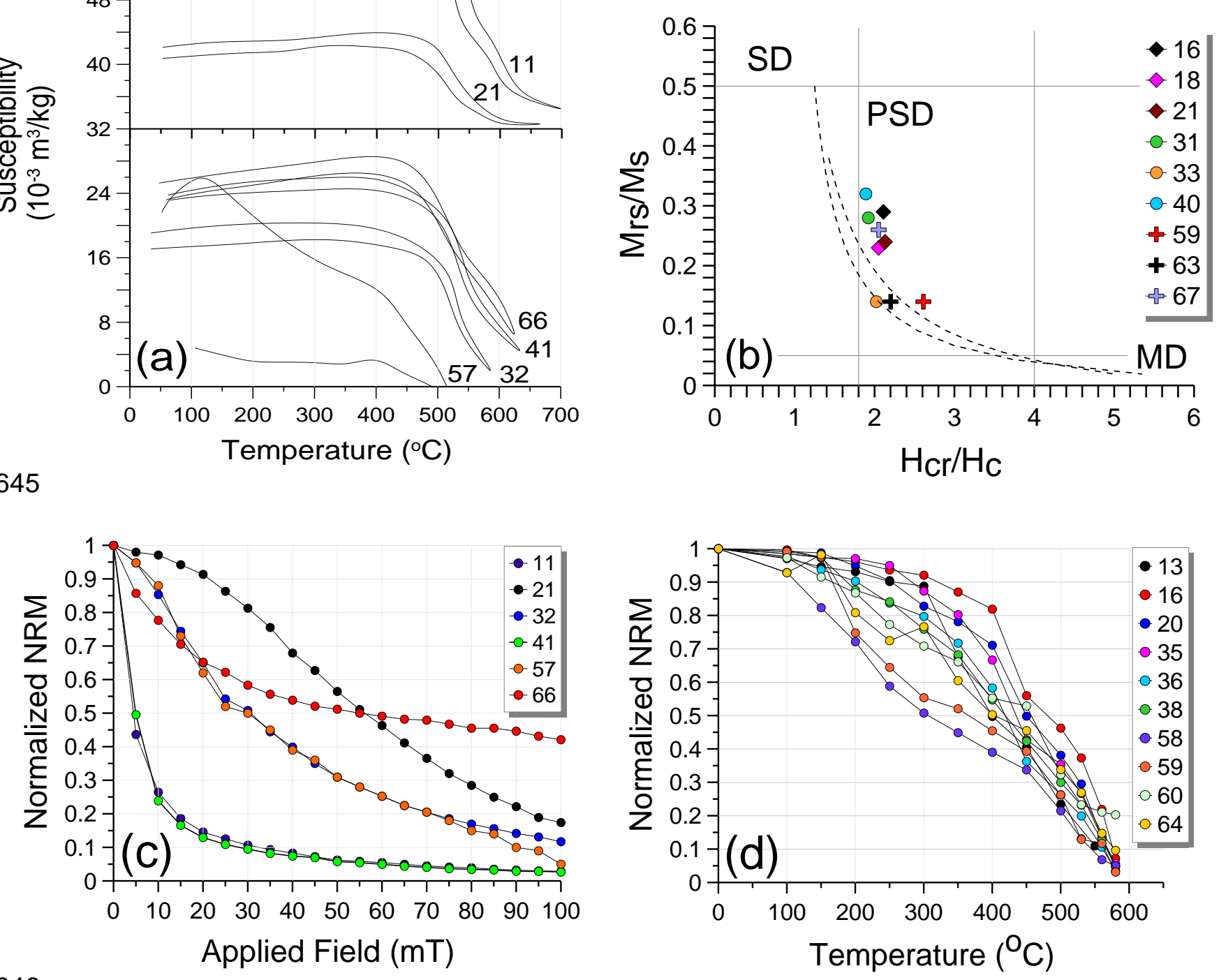

646

647

648 Figure 4. Rock magnetic results done in this study: (a) susceptibility vs. temperature curves;

649 (b) Day plot (Day et al., 1977) with thresholds for single domain (SD), pseudo single domain

650 (PSD), and multidomain (MD) shown as straight grey lines. Dashed curved lines represent

651 the SD-MD theoretical mixing curves, after Dunlop (2002); (c) intensity decay curves

652 obtained after alternating field demagnetization; (d) intensity decay curves after thermal

653 demagnetization. Numbers in each panel diagram represent core sample, see Figure 3. 
(a) profile $\mathrm{V}$

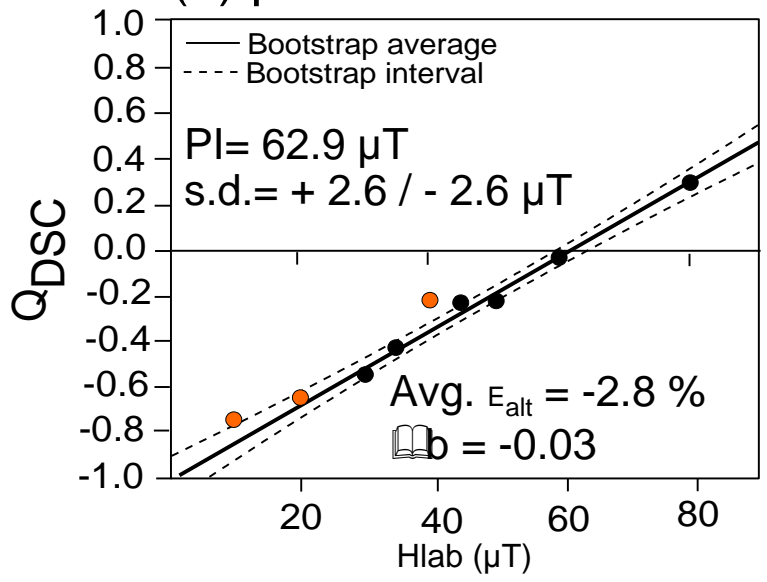

(c) profile HM

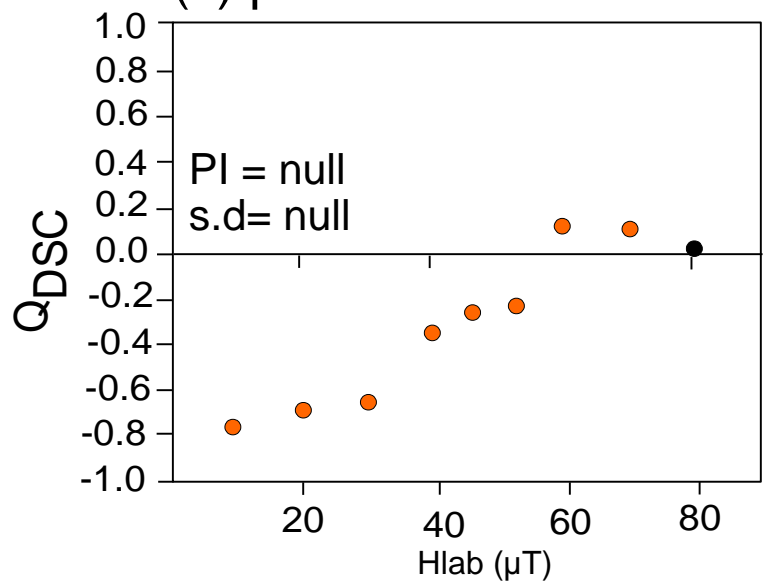

(b) profile HT

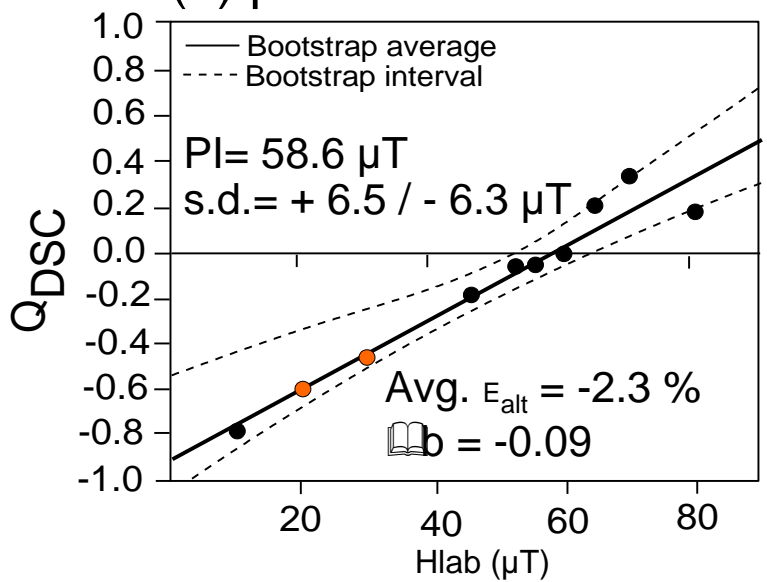

(d) profile $\mathrm{HB}$

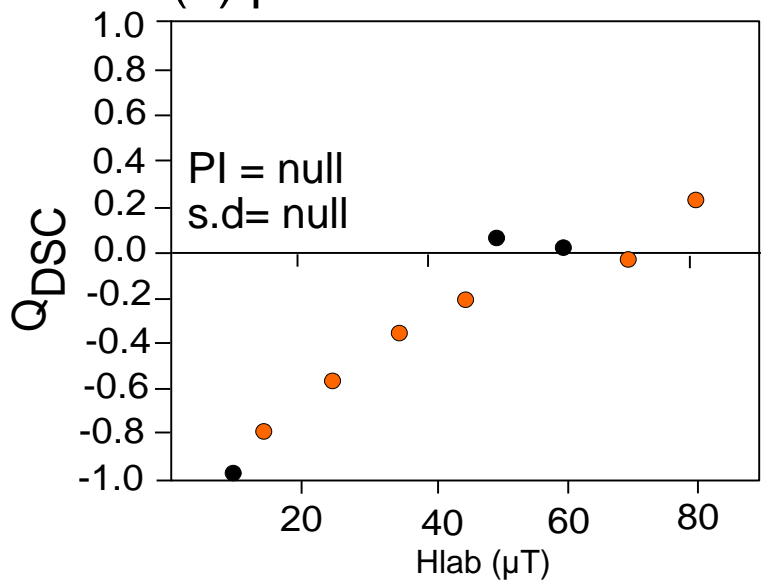

Figure 5. Multispecimen results obtained from four sampled profiles, after domain state correction (DSC). In each DSC protocol, the average alteration parameter (calt) and the intersection criterion $(\Delta \mathrm{b})$ are demonstrated to judge the credibility of the given results. Note that data were analyzed with MSP-Tool software (Monster et al., 2015b) where bootstrap

664 statistics were applied to calculate the mean (solid black line) and 95\% confidence interval 665 (dashed black lines lines). Black and orange circles represent those accepted and unaccepted data, respectively, based on the criteria limit defined in the present study. (a and b) represent accepted experiments done on profiles V and HT, as their specimens meet the designed 
668 criteria limit, and (c and d) represent unaccepted experiments from profiles HM and HB and 669 thus no PI mean could be calculated from these two profiles.

670 
(a) Reliable experiment: $\mathrm{V}+\mathrm{HT}$

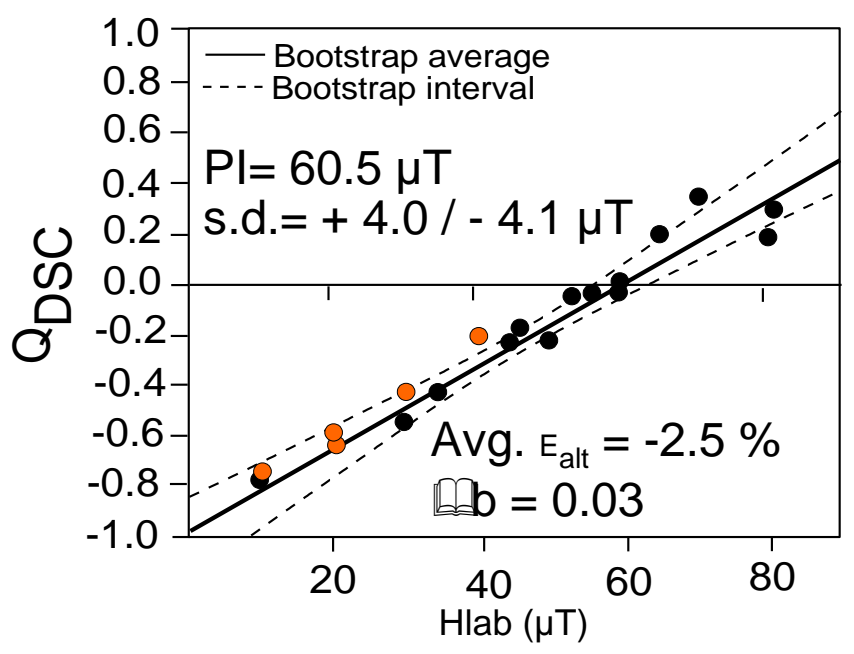

(b) Unreliable experiment: $\mathrm{HB}+\mathrm{HM}$

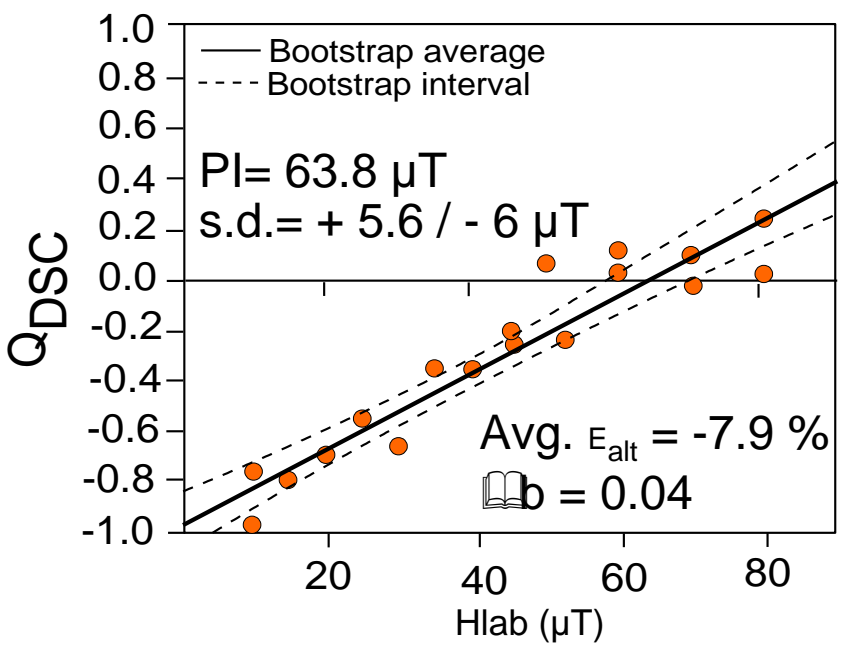

672

673

674

675

676 Figure 6. (a) Xitle PI mean value calculated from only reliable experiments done on V and

677 HT profiles. (b) represents unreliable experiments (from profiles HM and HB), and the

678 bootstrap mean (solid black line) and 95\% confidence interval (dashed black lines lines) are

679 shown to compare the Pi results obtained from reliable (a) and unreliable (b) data

680

681 
684 The supplementary materials consist of two figures. 


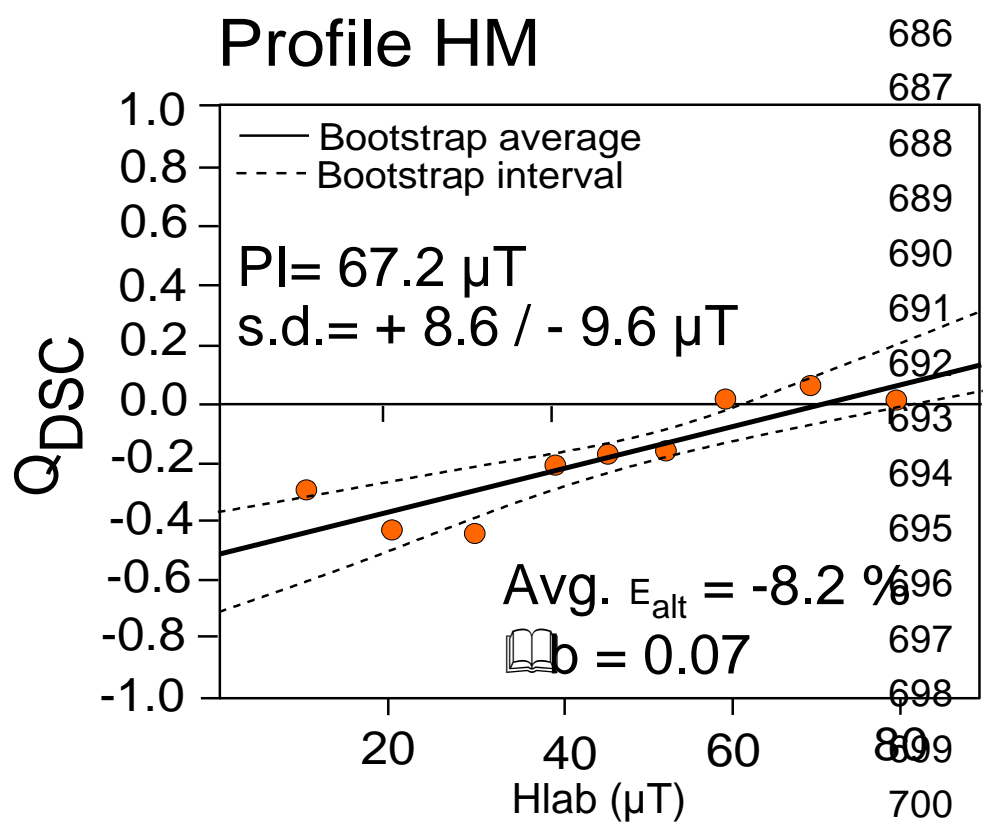

701

702

Figure S1. Multispecimen results obtained from central profile (HM), after domain state correction (DSC). The data were analyzed with MSP-Tool software (Monster et al., 2015b) where bootstrap statistics were applied to calculate the mean (solid black line) and 95\% confidence interval (dashed black lines lines). We note that in this profile we do not apply the selection criteria defined in the present study, as we just need to compare the unreliable data with reliable data. 


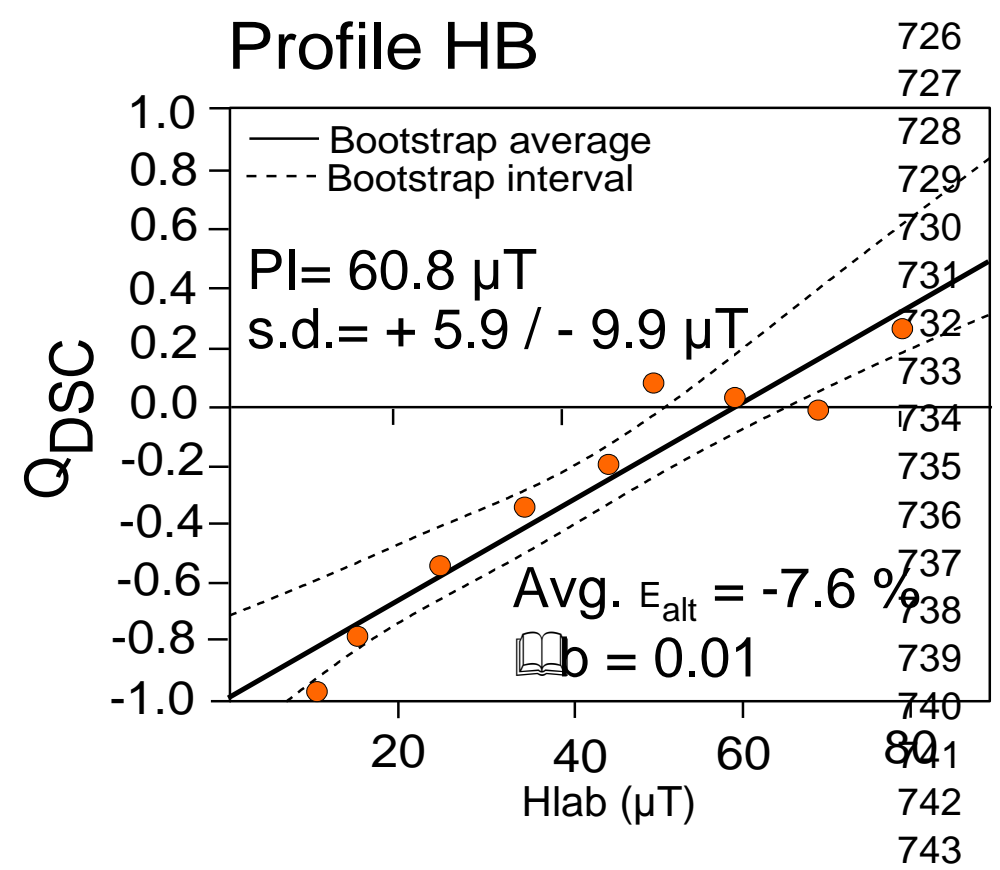

744 Figure S2. Multispecimen results obtained from bottom profile (HB). For details see Fig. 745 S2 caption.

746

747 